\title{
Optimal decisions and comparison of VMI and CPFR under price-sensitive uncertain demand
}

\author{
Yasaman Kazemi, Jun Zhang \\ North Dakota State University (United States) \\ yasaman.kazemi@ndsu.edu,jun.zhang@ndsu.edu
}

\section{A bstract:}

Purpose The purpose of this study is to make optimal decisions on retail price and order quantity for two advanced supply chain coordination mechanisms, Vendor Managed Inventory (VMI) and Collaborative Planning Forecasting and Replenishment (CPFR), under a pricesensitive uncertain demand environment, and to compare the performance of VMI and CPFR. Sensitivity analysis is also conducted to gain managerial insight.

Design/methoddogy/approadr Analytical models are first applied to formulate a profit maximization problem; furthermore, by applying simulation optimization solution procedures, the optimal decisions and performance comparisons are accomplished. Sensitivity analysis is also conducted to show how production cost and inventory holding cost affect optimal decisions and the total profits in VMI and CPFR.

Findings: The optimal decisions and expected total profits are impacted by the demand patterns, production cost, inventory holding cost, and internal transfer price. In addition, the results of the case study reveal that CPFR outperforms VMI in terms of higher expected total profit and lower retail price.

Research limitations/implications: This study only considers a single vendor and a single retailer in the supply chain structure. 
Practical implications: Knowledge obtained from this study about the performance of each coordination mechanism and decision making under uncertainty are critical to managers and industry practitioners who may apply the coordination mechanisms considered.

Originality/value This study includes the production cost in the mathematical model and combines it with price-sensitive demand under stochastic settings to maximize the total profit. Many studies have worked on information sharing within the supply chain; however, determining the optimal retail price and order quantity and comparing the performance of VMI and CPFR when the demand is price-sensitive and stochastic were not reported by the past literature.

Keywords: price-sensitive demand, VMI, CPFR, supply chain profit, simulation optimization, optimal order quantity, optimal retail price

\section{Introduction}

If companies intend to survive in today's competitive market, they need to develop supply chains that are robust and quickly respond to customer needs. In the meantime, supply chains are prone to uncertainties which have adverse ripple effects as they go upstream in the supply chain. The uncertainties can be reduced by availability of information on inventory levels, price, lead times, demand, etc. In addition, problems associated with the bullwhip effect can also be alleviated (Emerson, Zhou \& Piramuthu, 2009). The 'bullwhip effect' is a phenomenon in which the fluctuations in the order sequence grow larger for suppliers who are farther away from the customers (Ouyang, 2007). Observations in industry operations (Bamford \& Forrester, 2003; Forrester, 1958; Magee \& Boodman, 1967) macroeconomic data (Baganha \& Cohen, 1998; Holt, 1960; Kahn, 1987; Naish, 1994; Ramey \& Ramey, 1991) and simulated experiments such as the Beer Game (Goodwin \& Franklin, 1994; Simchi-Levi, Kaminsky \& Simchi-Levi, 2003; Sterman, 1989) have revealed huge extra supply chain costs due to this phenomenon(Cooke, 1998; Lee, Padmanabhan \& Whang, 1997).

Information sharing can mitigate the bullwhip effect because it introduces some degree of coordination and transparency across the chain and helps to allocate inventories across supply chain stages efficiently. The benefit of Information sharing reported in the literature varies considerably, and largely depends on the supply chain stage of interest and the customer demand scenario (Aviv, 2001, 2002; Cachon \& Fisher, 2000; Chen, 1998; Chen, Drezner, Ryan \& Simchi-Levi, 2000; Gavirneni, Kapuscinski \& Tayur, 1999; Lee, So \& Tang, 2000; Zhao \& Simchi-Levi, 2006). Information sharing has not only been found to reduce the bullwhip effect (order variability), but also to add value to the chain (Chen, et al., 2000; Gaur, Giloni \& 
Seshadri, 2005; Lee, et al., 1997; Lee, et al., 2000). Many studies have attempted to measure the value of information sharing (VOI) in a supply chain, which has been typically defined as the ratio of the supply chain cost with information sharing to supply chain cost without information sharing (Ketzenberg, Laan \& Teunter, 2006; Mohtadi \& Kinsey, 2005).

Most innovative supply chain coordination practices are, indeed, dependent on product, processes, and supply chain designs (Lee, et al., 2000). Over the past few decades, various collaboration practices have been applied through different approaches such as Vendor Managed Inventory (VMI) and Collaboration Planning Forecasting and Replenishment (CPFR).

Vendor Managed Inventory is a supply chain strategy wherein the vendor or supplier is given the responsibility of managing the customer's or retailer's stock (Gronalt \& Rauch, 2008). The concept of VMI was first successfully implemented between Wal-Mart and Procter \& Gamble in the late 1980s. Since then, other companies such as Shell Chemical, Campbell Soup, and Johnson \& Johnson have adapted the VMI mechanism as well.(Cachon \& Fisher, 2000). Because the retailer won't place orders in VMI, the ordering cost of the retailer is eliminated and the supplier is in charge of the replenishment process. Reduced administration costs for the retailer, as well as lower delivery costs for the vendor, are reported by Holmström, Främling, Kaipia and Saranen (2002). When the ordering responsibility is shifted to the vendor, the who was involved in the ordering process can adapt his/her activities to customer service . Kuk (2004), also indicated that implementing VMI can lower the incidence of stock-out situations, increase the customer service level, and reduce costs due to an increase in inventory turnover and a decrease in the levels of safety stock. Zhao \& Simchi-Levi (2006) applied a deterministic model of the VMI system to examine the cost saving due to the VMI program, and found out that the higher the ratio of inventory holding cost or the higher the replenishment lead-time ratio of the manufacturer to the retailer, the greater the total inventory holding cost saving for the manufacturer will be gained.

The issue of demand visibility attracted the attention of some researchers in supply chain. Småros \& Holmström (2000), investigated the effects of increased demand visibility in the supply chain, and their simulation model demonstrated that by combining the traditional ordering data and sell-through information available from VMI costumers, the manufacturer can benefit from even a partial increase in visibility.

Vendor Managed Inventory is a particular subject of interest in the bullwhip effect (Disney \& Towill, 2003). Potentially, VMI offers two possible sources of bullwhip reduction. First, there is an elimination of one layer of decision-making in the supply chain. Second, some information time delays will be removed; therefore, both factors can be utilized to damp down the bullwhip effect (Disney \& Towill, 2003).

Despite all the success stories about VMI, many research suggest otherwise. Increased level of details required for planning the approach, expensive administration costs, establishing trust 
among the members of the supply chain and strong commitment are among the limitations reported using VMI in a supply chain

Collaborative Planning, Forecasting, and Replenishment (CPFR) is defined as a "formalized process between two trading partners used to agree upon a joint plan and forecast, monitor success through replenishment, and recognize and respond to any exceptions" (Holmström et al., 2002). CPFR is an attempt to coordinate different activities within the supply chain trading partners such as production and purchase planning, demand forecasting, and inventory replenishment department (Fliedner, 2003). One advantage of CPFR over VMI is the elimination of uncertainty through improved communications and collaborations among supply chain trading partners (Attaran \& Attaran, 2007). Since CPFR increases information sharing in the whole supply chain and enhances demand visibility, the uncertainty may be reduced as a result of reduction in the information distortion or the bullwhip effect. Raghunathan (1999) investigated the benefit of CPFR in a supply chain consisting of one manufacturer and two independent retailers based on the classic newsvendor model. The results of the model analyses indicate that, compared with the traditional system, the manufacturer's cost is reduced when the CPFR is applied.

Aviv (2001) developed a complicated model to address the CPFR system based on a two stage supply chain with a single product. The author constructs three different scenarios based on forecasting and ordering policies- baseline setting, local forecasting setting, and collaborative forecasting setting. The results showed that the local forecasting outperforms the base setting by $11.4 \%$, and collaborative forecasting would cost less by an average of $19.43 \%$ than in the base setting. Aviv (2004), developed a descriptive dynamic model of a simple supply chain consisting of single manufacturer and single retailer where the production capacity is limited. The proposed model indicated that CPFR leads to substantial benefits to the supply chain system, but the magnitude depends on the manufacturer's ability to collect the advanced demand information and to revise the production plans. Attaran and Attaran (2007) studied several cases in which CPFR was implemented, and concluded that companies experience variation in demand, buy or sell a product on a periodic basis, and those that deal in highly differentiated products will benefit the most.

Many studies have used simulation approach in order to analyze supply chain systems (Disney \& Towill, 2003; Lau, Huang \& Mak, 2004; Southard \& Swenseth, 2008; Waller, Johnson \& Davis, 1999; Zhang, 2007; X. Zhao, Xie \& Leung 2002). In addition, Sari (2008), compared CPFR and VMI via a comprehensive simulation model. The results revealed that the reduction in total supply chain cost derived in CPFR is significantly higher than in VMI, and the customer service level is also much higher in CPFR. Another simulation study which was conducted by Ganeshan, Boone and Stenger (2001) et al., indicated that CPFR increases the fill rate, decreases supply chain inventories, reduces supply chain cycle time, and increases shareholder wealth. 
Although VMI and CPFR have been studied and compared widely in literature, the performance of VMI and CPFR under price-sensitive demand has not been evaluated. However, there exists several examples of products that their demands are sensitive to the retail price (Ouyang, 2007). Therefore, this paper focuses on developing mathematical models to determine the optimal retail price and order quantity, the most important decisions of VMI and CPFR, under stochastic price-sensitive demand. Comparison of VMI and CPFR is also provided. Sensitive analysis is also conducted to gain managerial insight.

The rest of the paper is structured as follows: the following section discusses the system configuration. Section 3 presents the problem statement. Mathematical modeling and solution procedure are presented in Section 4 . Section 5 presents the case study and results. Finally, the conclusion and future research are presented in Section 6.

\section{System configuration}

The supply chain studied in this paper consists of the following major components: one manufacturer, one warehouse, a retailer and final customers. The manufacturer is considered as the vendor throughout the paper and it is assumed that the manufactured goods are stored in the retailer's warehouse and they will be replenished by the manufacturer. The material flow starts from the upstream (manufacturer), on the other hand, the information flow depending on the type of coordination, is backward in VMI and is shared with the whole supply chain in CPFR. With the enhanced level of information sharing in VMI and CPFR, the stochastic pattern of demand can be traced and optimal decisions can be reached in order to maximize the profit of each member of the supply chain and the supply chain as a whole.

The demand is assumed to be stochastic and price sensitive. Demand with price dependence can be roughly categorized into two cases: additive demand types and Multiplicative demand types (Dana Jr \& Petruzzi, 2001). Additive demand types are such that $d(P)=\alpha-\beta P$ where $\alpha$ and $\beta$ are the intersection and the slop of the demand function respectively. $P$ is the retail price and, and $d(P)$ represents the price-sensitive demand. The multiplicative demand types are such that $d(P)=a P^{b}$, where $a$ and $b$ are constant values. In this study, the demand follows a similar structure to the additive demand type, and the parameter for the slope is stochastic.

\subsection{Configurations of VMI and CPFR}

Figure 1 shows the configuration of VMI system. In the VMI system the manufacturer is responsible for managing the inventories at the retailer's warehouse, and therefore he/she is in charge of the holding cost. Since the retailer won't place orders, the manufacturer receives information about the market demand directly from the final customers and he/she determines the order quantity. 


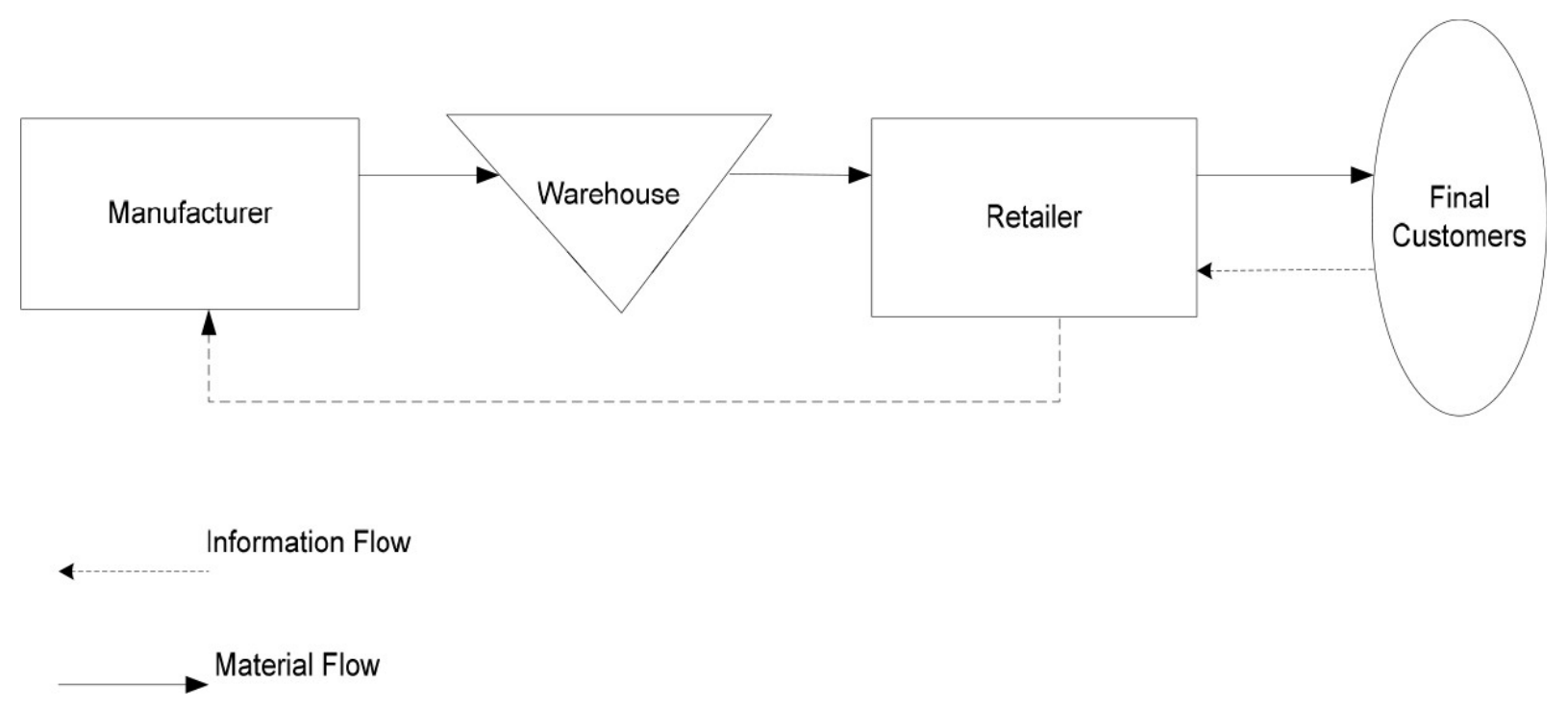

Figure 1. The Configuration of VMI System

Figure 2 illustrates the CPFR system. In the CPFR system, the retailer and manufacturer share the authority over the entire system. The parties make joint decisions about managing the operations over the whole system including production, processing, and distribution. In addition, there is no limit to transfer information between the retailer and the manufacturer in the supply chain. The market demand is directly transferred to both parties and the retailer also receives the information about the production plan from the manufacturer and uses this information to manage the inbound logistics and distribution process.

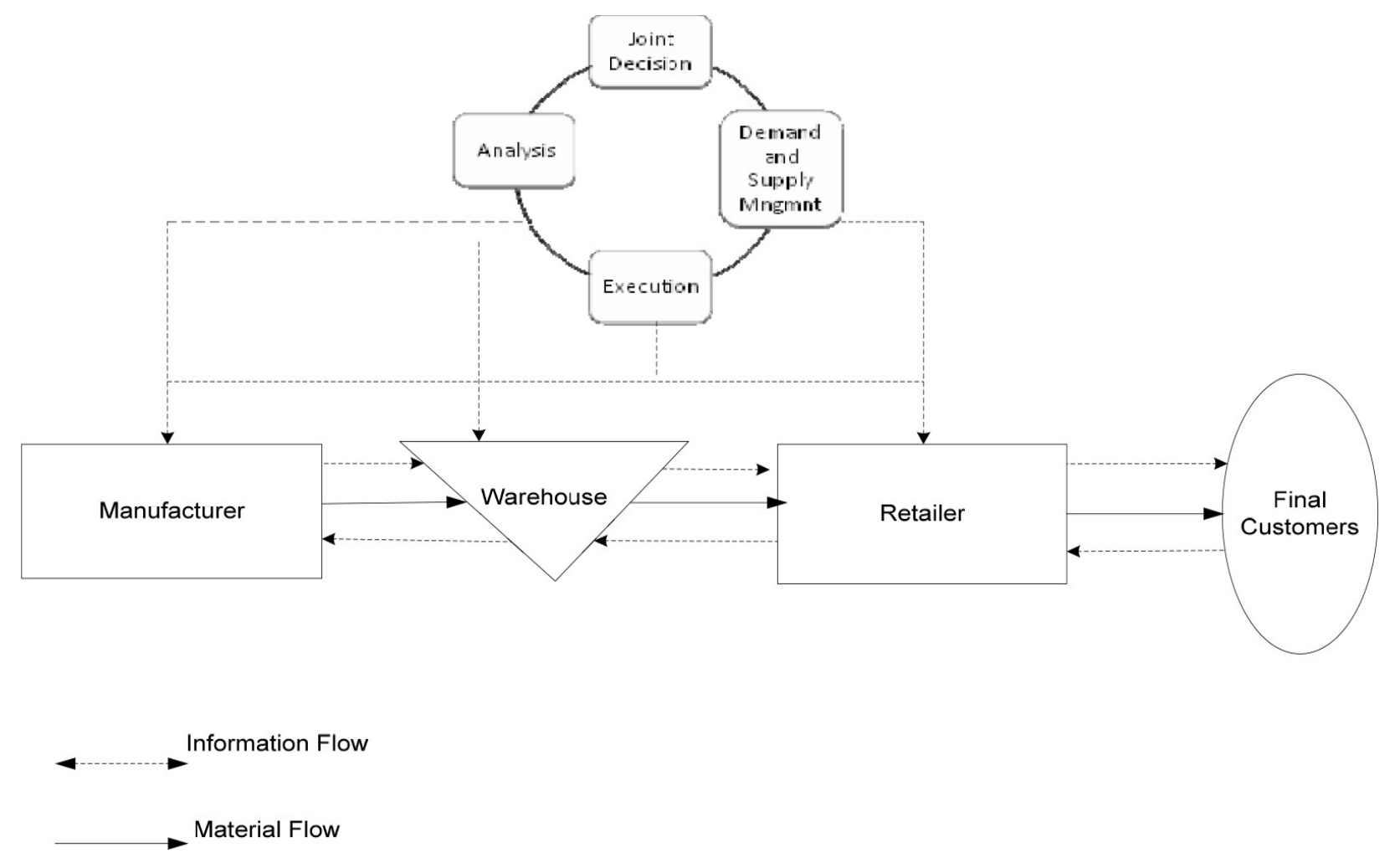

Figure 2. The Configuration of CPFR System 


\subsection{Notations and Basic Assumptions}

Table 1 presents the notations and parameters used in this paper.

\begin{tabular}{|c|c|}
\hline Notation & Description \\
\hline $\mathrm{TP}_{\mathrm{M}}{ }^{\mathrm{V}}$ & Total profit of manufacturer in VMI \\
\hline $\operatorname{TP}_{\mathrm{B}}{ }^{\mathrm{V}}$ & Total profit of retailer in VMI \\
\hline $\mathrm{TP}_{\mathrm{M}}{ }^{\mathrm{C}}$ & Total profit of manufacturer in CPFR \\
\hline $\operatorname{TP}_{\mathrm{B}}{ }^{\mathrm{C}}$ & Total profit of retailer in CPFR \\
\hline$R$ & Annual production rate \\
\hline$D$ & Stochastic demand which is a function of $a^{\prime}$ and $b^{\prime}$ \\
\hline$A_{M}^{v}$ & Set up cost of manufacturer in VMI \\
\hline$A_{M}{ }^{c}$ & Set up cost of manufacturer in CPFR \\
\hline$A_{B}{ }^{v}$ & Ordering cost of retailer in VMI \\
\hline$A_{B}{ }^{c}$ & Ordering cost of retailer in CPFR \\
\hline$Q$ & Production quantity, order quantity \\
\hline$h_{M}{ }^{v}$ & Annual inventory holding cost of manufacturer in VMI \\
\hline$h_{M}{ }^{c}$ & Annual inventory holding cost of manufacturer in CPFR \\
\hline$h_{B}{ }^{v}$ & Annual inventory holding cost of retailer in VMI \\
\hline$h_{B}{ }^{c}$ & Annual inventory holding cost of retailer in CPFR \\
\hline$c$ & Unit purchasing price of retailer (transfer price) \\
\hline$P$ & retailer's unit selling price \\
\hline$v$ & Unit production cost \\
\hline$b^{\prime}$ & Slope of demand with a known probability distribution \\
\hline$a^{\prime}$ & Intercept value of demand \\
\hline
\end{tabular}

Table 1. Model Notation for Profit Comparison

In addition, the following assumptions are made in this paper:

- The model deals with single vendor and single retailer for a single product.

- The demand is a function of selling price $(P) ; D(P)=a^{\prime}-b^{\prime} P$, where $\left(a^{\prime}>b^{\prime}>0\right)$ and $b^{\prime}$ is stochastic.

- The production rate is finite and greater than the demand rate.

- Transfer price $(c)$ is the price which manufacturer sells its products to the retailer. It is assumed that $c$ is determined by the negotiation between two parties.

- The inventory will be reviewed continuously and the retailer orders a lot size of $Q$ when the on-hand inventory reaches the reorder point.

- The planning time horizon is finite.

- The ordering lead time assumed to be constant.

- Shortage is not allowed.

- The product life cycle is greater than the planning period. 
- There is a single upstream manufacturer $(M)$ and a single retailer $(B)$ as the downstream partner.

- The manufacturer must use the retailer to reach final customers.

- Demand of the retailer is stochastic and price-sensitive.

- A demand rate is assumed for the whole year, and whenever inventory reaches zero the retailer will be replenished by $Q$, therefore, the cycle times will be unequal and there is no shortage or excess inventory at the end of each period or cycle.

- The manufacturer capacity constraints are ignored.

- In VMI the manufacturer is responsible for paying the inventory holding cost at the retailer's warehouse.

\section{Problem statement}

The main objective of this study is to determine the optimal decisions and to compare the performance of VMI and CPFR under a price-sensitive demand.

Optimal decisions of the retail price and order quantity are determined in order to maximize the profits of the vendor and the retailer. The performance of each of the mechanisms under a stochastic price sensitive demand will be measured and compared in order to provide managerial insights. The order quantity and selling price in each supply chain structure is derived by maximizing the total profit and the results are served as a benchmark to analyze the impact of implementing VMI and CPFR mechanisms under demand uncertainty.

While most previous studies consider only costs, this study evaluates the system performance with profit. However, due to the fact that the analysis is stochastic, the expected value of profit will be considered throughout the study. The optimal order quantity $\left(Q^{*}\right)$ and the retail price $\left(P^{*}\right)$ are also considered as decision variables throughout the study in each of the supply chain mechanisms.

Table 2 illustrates the decision variables used in each of the supply chain coordination mechanisms. In VMI the vendor decides the order quantity and the retailer decides the retail price. However, In CPFR the order quantity and retail price are determined jointly.

\begin{tabular}{|c|r|r|}
\hline Supply chain system & Vendor's decision & Retailer's decision \\
\hline VMI & Order quantity $(Q)$ & Retail price $(P)$ \\
\hline CPFR & Retail price $(P)$, Order quantity $(Q)$ \\
\hline
\end{tabular}

Table .2 Decision Variables in VMI and CPFR 


\section{Mathematical modeling and solution procedure}

In this section, mathematical models for VMI and CPFR are presented to determine the optimal retail price and order quantity in order to maximize the total profit for each partner in the supply chain.

\subsection{Economic measures in VMI supply chain}

Because the demand is stochastic, we are seeking the expected value of the profit. The expected total profit of the retailer would be equal to subtracting the revenues from the payments to the manufacturer which is shown in Equation (1):

$$
E\left(T P_{B}^{V}\right)=E(D \cdot P-c \cdot D)=\int_{0}^{\infty} D \cdot f(D) \cdot(P-c) d D
$$

Where $f(D)$ is the probability density function of the demand.

The expected total profit of the manufacturer consists of the following components and it is shown in Equation (2):

Expected revenue - Expected set up costs of manufacturer and retailer - Expected inventoryholding costs of the manufacturer and retailer- Expected production cost

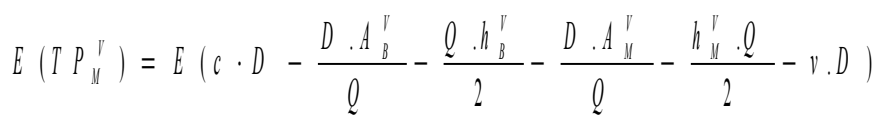

$$
\begin{aligned}
& =\int_{0}^{\infty}\left(C \cdot D \cdot f(D)-\frac{D \cdot f(D) \cdot A_{B}^{\nu}}{2}-\frac{D \cdot f(D) \cdot A_{u}^{\nu}}{2}-v \cdot D \cdot f(D) d D\right)-\frac{h_{u}^{\nu} \cdot Q}{2}-\frac{Q \cdot h_{B}^{V}}{2}
\end{aligned}
$$

In order to find the optimal values of order quantity $\left(Q^{*}\right)$ and retail price $\left(P^{*}\right), P^{*}$ should be determined to maximize equation (1), and $Q^{*}$ should be determined to maximize equation (2) given the value of $P^{*}$.

\subsection{Economic measures in CPFR supply chain}

In CPFR, with a full knowledge of costs and market demand, the centralized decision makers determine the optimal values of retail price, and order quantity. The total joint profit of the entire supply chain is calculated as follows:

Expected joint profit $=$ Expected revenue - Joint set up cost - Inventory holding costs of the manufacturer and retailer - Expected production cost 


$$
\begin{aligned}
& E\left(T P_{j}^{c}\right)=E\left(a^{\prime} \cdot P-b^{\prime} \cdot P^{2}-\frac{D \cdot\left(A_{M}^{c}+A_{B}^{c}\right)}{l}-\frac{h_{B}^{c} \cdot Q}{2}-\frac{h_{M}^{c} \cdot Q}{2}-v \cdot D\right) \\
& =\int_{0}^{\infty}\left(a^{\prime} \cdot P-b^{\prime} \cdot P^{2}-\frac{h_{B}^{c} \cdot Q}{2}-\frac{h_{M}^{c} \cdot Q}{2}\right)-\left(D \cdot f(D) \cdot \frac{\left(A_{M}^{c}+A_{B}^{c}\right)}{2}-v \cdot D \cdot f(D) d D\right)
\end{aligned}
$$

The optimal values of order quantity $\left(Q^{*}\right)$ and retail price $\left(P^{*}\right)$ are determined simultaneously from equation (3) in order to maximize the total joint profit. However, decisions about operations are jointly made by both parties in order to minimize the total supply chain cost. In order to split the joint profit of the whole supply chain, Equation (4) and Equation (5) are applied to derive the profit of the manufacturer and retailer, respectively(Sajadieh \& Akbari Jokar, 2009).

$$
\begin{aligned}
& T P_{M}^{C}=\frac{T P_{M}^{V}}{T P_{M}^{V}+T P_{B}^{V}} \times T P_{J}^{c} \\
& T P_{B}^{C}=\frac{T P_{B}^{V}}{T P_{M}^{V}+T P_{B}^{V}} \times T P_{J}^{c}
\end{aligned}
$$

\subsection{Solution procedure}

Since it is difficult to analytically solve Equations (1), (2) and (3) to find the optimal solution, simulation optimization searching algorithm in excel was used to find the optimal values for order quantity $\left(Q^{*}\right)$ and retail price $\left(P^{*}\right)$ in VMI and CPFR under the price sensitive demand. To derive the optimal values of $Q$ and $P$ in the VMI supply chain, the following steps are taken:

- Set an initial value for the retail price $(P)$.

- Generate N random samples of $b^{\prime}$ according to its probability distribution. Each sample of $b^{\prime}\left(b_{i}^{\prime}\right)$ can be used to calculate the sample demand $\left(D_{i}\right)$ by applying the equation $D_{i}=a^{\prime}-b_{i}^{\prime} P$.

- For each demand scenario, $\left(D_{i}\right)$, calculate the retailer's profit by using $D_{i} P-c D_{i}$, then calculate the expected total profit of retailer by using $E\left(T P_{B}^{\prime}=E(D, P-C, D)\right) \approx$ $\frac{1}{N} \sum_{i=1}^{N}\left(D_{i}, P-C \cdot D_{i}\right)$

- Use Excel optimal searching algorithm (by changing the $P$ ) to determine optimal retail price $P^{*}$ in order to maximize the expected profit of retailer.

- Set an initial value of order quantity $(Q)$. 
- For each demand scenario, calculate the manufacturer's profit by using the profit equation profit $=c \cdot D_{i}-\left(\frac{D_{i} \cdot A_{b}^{r}}{\ell}-\frac{\ell \cdot h_{B}^{r}}{2}-\frac{D_{i} \cdot A_{\|}^{\nu}}{\ell}-\frac{h_{\|}^{\nu} \cdot \ell}{2}-v \cdot D_{i}\right)$. Then calculate the expected profit of manufacturer by using $E\left(T P_{j}^{c}\right) \approx \frac{1}{N} \sum_{i=1}^{N} C \cdot D_{i}-\left(\frac{D_{i} \cdot A_{B}^{r}}{l}-\frac{\ell \cdot h_{B}^{r}}{2}-\frac{D_{i} \cdot A_{\|}^{r}}{\ell}-\frac{h_{1}^{r} \cdot Q}{2}-v \cdot D_{i}\right) \cdot$

- Use Excel optimization searching algorithm to determine optimal order quantity $Q^{*}$ in order to maximize the expected profit of manufacturer.

In CPFR, the optimal values of $P$ and $Q$ are determined in the following steps:

- Set initial values for the retail price and order quantity, $P$ and $Q$, respectively.

- Generate N random samples of b'according to its probability distribution. Each sample of $\left.b^{\prime}\left(b_{i}^{\prime}\right)\right)$ can be used to calculate the sample demand $\left(D_{i}\right)$ by applying the equation $D_{i}=a^{\prime}-b_{i}{ }^{\prime} P$.

- For each demand scenario $\left(D_{i}\right)$ calculate the joint profit by using the joint profit

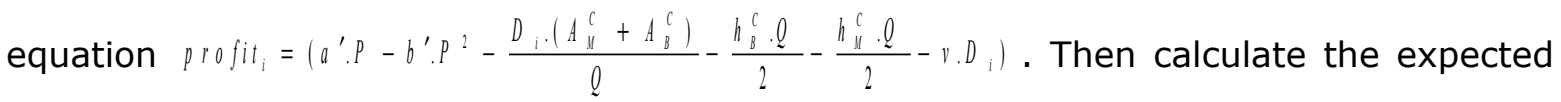
joint profit by using $E\left(T P_{j}^{c}\right) \approx \frac{1}{N} \sum_{i=1}^{N} a^{\prime}, P-b^{\prime}, P^{2}-\frac{D_{i} \cdot\left(A_{\mu}^{c}+A_{B}^{c}\right)}{l}-\frac{h_{B}^{c} \cdot \ell}{2}-\frac{h_{\mu}^{c} \cdot Q}{2}-v \cdot D_{i}$.

- Use Excel optimal searching algorithm to determine $Q^{*}$ and $P^{*}$ simultaneously in order to maximize the expected joint profit.

- Derive the individual manufacturer's and retailer's profits from equations (4) and (5) with regard to the optimal values of joint profit, and optimal values of manufacturer and retailer profits in VMI.

\section{Case study}

This section presents a case study to demonstrate the proposed procedure to determine the optimal order quantity $\left(Q^{*}\right)$, the retail price $\left(P^{*}\right)$ under stochastic price-sensitive demand for VMI and CPFR, respectively. Comparison and sensitivity analysis are conducted to gain managerial insights as well.

\subsection{Parameter setting}

In order to conduct the study, first, we generated three scenarios of stochastic price sensitive demand by applying additive price-sensitive demand equation $D=a-b P$. It is assumed that the 
Slope of demand $\left(b^{\prime}\right)$ follows uniform distribution: $b^{\prime} \sim U[b-\beta, b, b+\beta, b]$ where $b$ is assumed to be a constant value and $\beta$ is considered to be equal to $.1, .3$ or .7 in each simulation run respectively. Therefore, the demand function is derived as $D \sim U\left[a^{\prime}-(b-\beta . b) P, a^{\prime}+(b+\beta, b) P\right]$ where $P$ is the selling price. A representative histogram of a sample market demand for the selected parameters is shown in Figure 3 to clarify the distribution of the market demand.

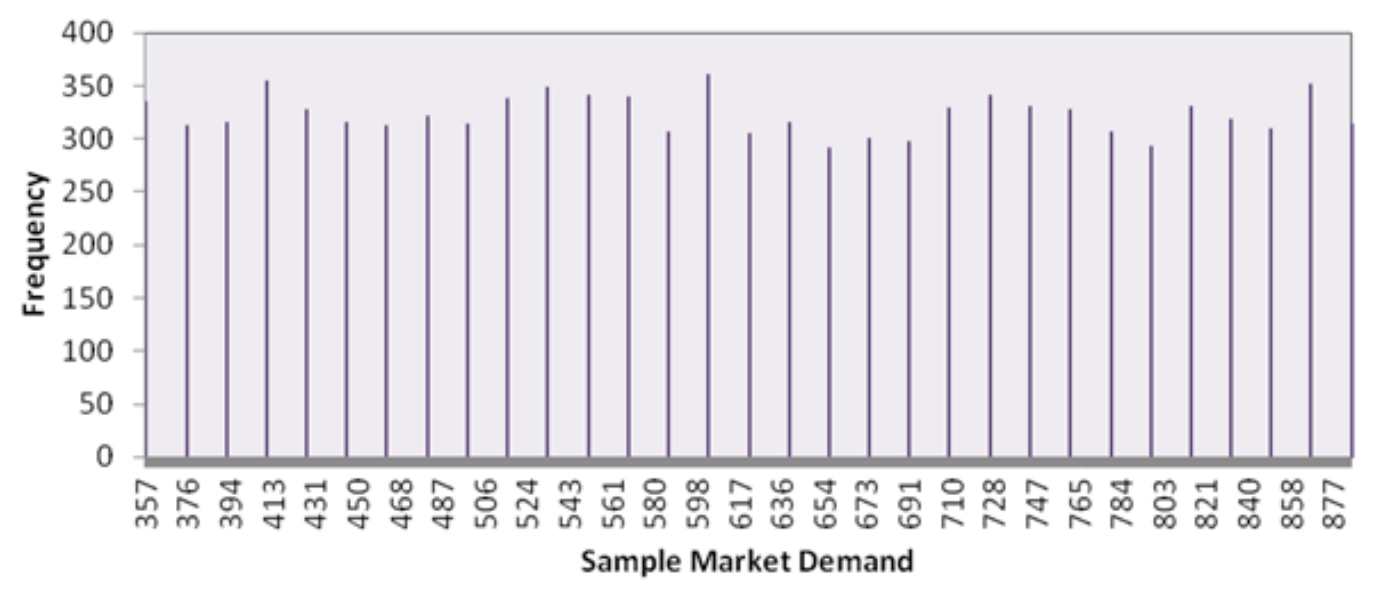

Figure 3. Histogram of a sample market demand when $\beta=.1$

A total of $\mathrm{N}=10,000$ samples under each demand scenario are considered to conduct the case study. In every run, when the demand is generated, the initial value of retail price $(P)$ is set to 1 and the optimal price $\left(P^{*}\right)$ that maximizes retailer's profit in VMI is calculated by using Excel optimal searching algorithm. In the next step, using an initial value of 1 for order quantity, the maximum profit for the manufacturer and the optimal value for the order quantity are found. This process repeats for CPFR supply chain with a slightly different optimization process. In CPFR, we maximize the joint profit using both initial values for the retail price and order quantity; therefore, the optimal values are derived simultaneously. Then, according to Equations (4) and (5), the individual profits for the manufacturer and the retailer are calculated.

\begin{tabular}{|c|c|}
\hline Parameter & Value \\
\hline$a^{\prime}$ & 1500 \\
\hline$b$ & 50 \\
\hline$h_{B}{ }^{v}, h_{B}{ }^{c}$ & .3 \\
\hline$h_{M}{ }^{v}, h_{M}{ }^{c}$ & .3 \\
\hline$A_{B}{ }^{c}, A_{B}{ }^{v}$ & 12 \\
\hline$A_{M}{ }^{v}, A_{M}{ }^{c}$ & 40 \\
\hline$v$ & 1 \\
\hline$c$ & 5.2 \\
\hline
\end{tabular}

Table 3. Parameters Used in the Case Study 
In order to determine an initial value for transfer price $(c)$ in CPFR and VMI, it is reasonable to expect that $c>v+\frac{A_{\Perp}}{\ell}$ since the manufacturer would never operate under a loss. Using a negotiation approach the upper and lower bounds for the transfer price in VMI are derived as $1.3<c<30$. After conducting further analysis to determine the value of transfer price, it is obtained as 5.2 in VMI. Table 3 summarizes the parameters used in the case study. The data is obtained from a fabricated industry close to the local practice.

\subsection{Results and discussion}

The results derived from the case study for each supply chain mechanism are shown in Table 4 and Table 5. Comparison of decisions and the total profit is depicted in Figure 3.

\begin{tabular}{|c|c|c|r|r|r|}
\hline Demand variation & $\mathbf{Q}^{*}$ & $\boldsymbol{P}^{*}$ & Manufacturer's profit & \multicolumn{1}{c|}{ Retailer's profit } & Expected total profit \\
\hline $10 \%$ & 395.21 & 15.57 & 2431.87 & 7836.43 & 10268.30 \\
\hline $30 \%$ & 395.21 & 15.55 & 2431.22 & 7820.08 & 10251.29 \\
\hline $70 \%$ & 395.21 & 15.50 & 2429.90 & 7787.29 & 10217.19 \\
\hline
\end{tabular}

Table 4. The Case study Results for CPFR

\begin{tabular}{|c|c|c|r|r|r|}
\hline Demand variation & $\boldsymbol{Q}^{*}$ & $\boldsymbol{P}^{*}$ & Manufacturer's profit & Retailer's profit & Expected Total profit \\
\hline $10 \%$ & 366.53 & 17.61 & 2383.78 & 7681.46 & 10065.23 \\
\hline $30 \%$ & 366.43 & 17.57 & 2382.98 & 7664.94 & 10047.92 \\
\hline $70 \%$ & 366.32 & 17.52 & 2381.38 & 7631.82 & 10013.20 \\
\hline
\end{tabular}

Table 5. The Case Study Results for VMI
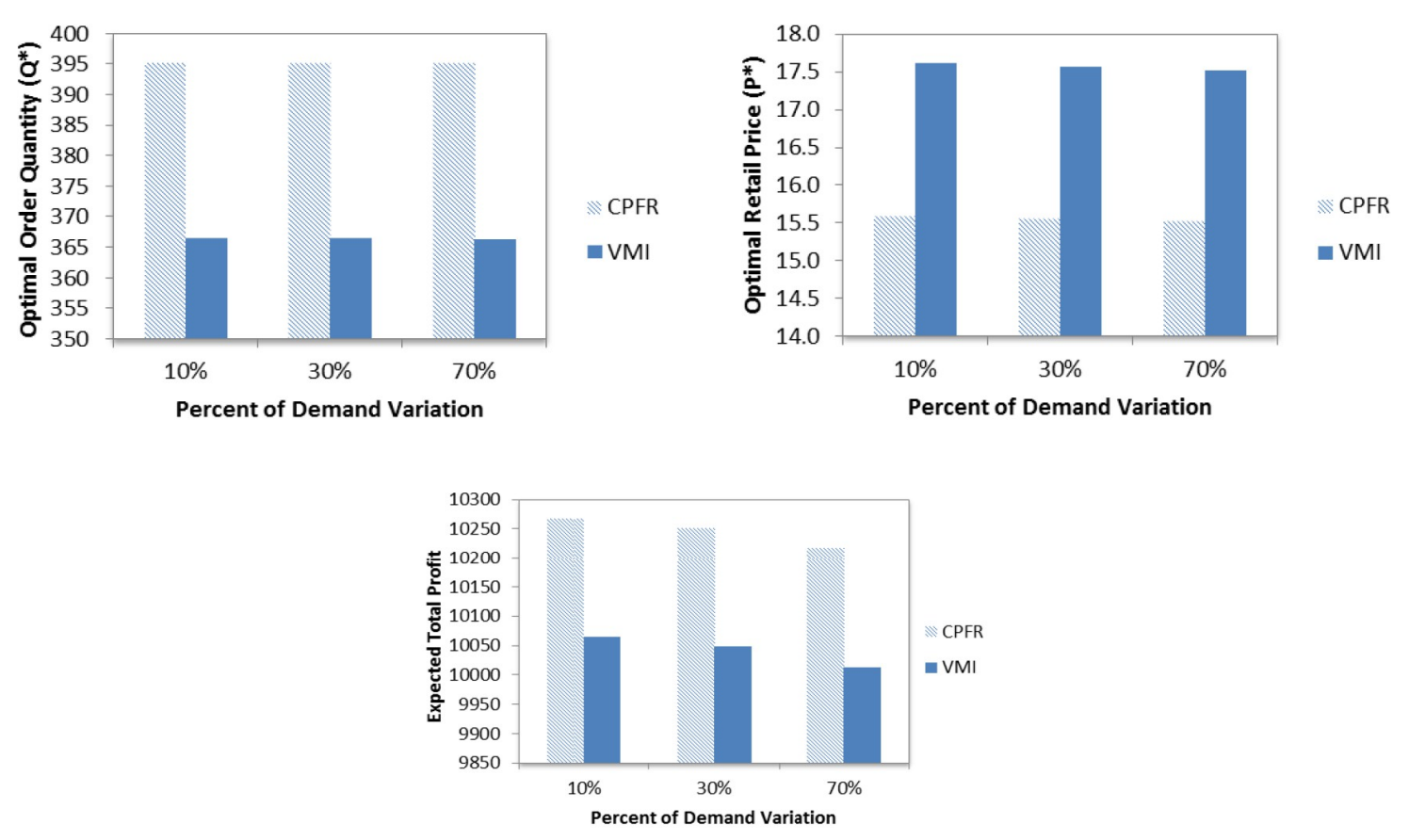

Figure 4. Comparison of $Q^{*}, P^{*}$ and Expected ToTal Profit under 
The above results and comparison imply that:

- In CPFR, when demand variation increases, optimum retail price decreases in order to attract more demand, and the expected total profit decreases. In VMI, the similar pattern is found. When demand variation increases, optimum retail price and order quantity decrease, and the expected total profit decreases. This implies that managers should control the demand variation to a minimum level in order to maintain high profit.

- The optimum retail price $\left(P^{*}\right)$ is lower in CPFR than in VMI under each demand scenario. This is a significant advantage for CPFR because, in reality, when the market demand is not predictable and stochastic, implementing CPFR can result in higher profit. In other words, CPFR is more robust to the changes and variations of market demand. This benefits the production planning, inventory management, forecasting and scheduling; moreover, it makes CPFR a more reliable mechanism to employ in the supply chain.

- The optimal order quantity $\left(Q^{*}\right)$ is higher in CPFR, which implies less stock-outs at the retailer. According to the case study's parameter setting, the set up cost is higher than the inventory holding cost and the production costs; therefore, the larger $Q$ indicates more sales and more profit for the whole supply chain.

- CPFR supply chain system has a higher total profit than VMI when the demand is price sensitive. In other words, CPFR performs more effectively when the demand fluctuates as a percentage in price. This claim is also true about the manufacturer and retailer individual profits as well. Compared to VMI, CPFR gains more profit for each of the supply chain partners when the demand is price sensitive.

\subsection{Sensitivity analysis}

In order to gain more managerial insight about the decision variables a sensitivity analysis was conducted to discover how parameters impact the performance of the supply chain. Among the parameters studied, the production cost and the manufacturer's holding cost are identified as the important parameters which have a significant impact on the supply chain performance and on the decision variables. As a result, two sets of sensitivity analyses under the same demand variation are conducted and the results are shown in the following section.

The impact of the production cost on optimal order quantity and optimal retail price in VMI

As it is shown in Figure 5, when the production cost $(v)$ increases in VMI mechanism, the transfer price $(c)$ increases, and therefore, it would impact the optimal retail price $\left(P^{*}\right)$. The more the retailer pays to purchase the goods from the manufacturer, the higher the retail price would be. Since the demand is price sensitive, when retail price increases, the demand decreases and the 
optimal order quantity $\left(Q^{*}\right)$ decreases. Also according to Equation 2, when the production cost increases, it would be reasonable to expect that the order quantity decreases.
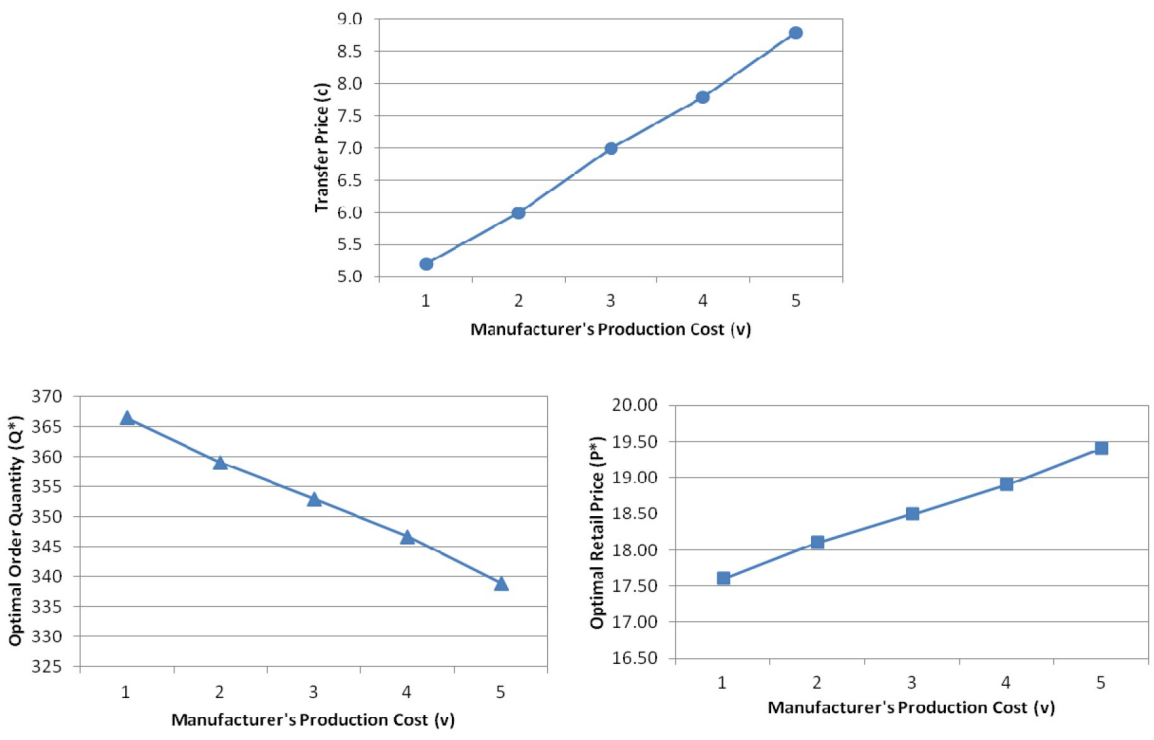

Figure 5. Impact of Production Cost on $Q^{*}, P^{*}$, and $c$ in VMI

The impact of the manufacturer's holding cost on optimal order quantity and optimal retail price in VMI

Figure 6 shows the impact of changing the manufacturer's holding cost $\left(h_{M}^{v}\right)$ on the transfer price $(c)$, the optimal retail price $\left(P^{*}\right)$ and the order quantity $\left(Q^{*}\right)$ in VMI. It is implied that when the manufacturer pays more cost to hold inventory, he or she would increase the transfer price in order to compensate for the increase in his/her cost. Therefore, when $c$ increases, it makes the retail price increase and therefore the optimal order quantity decreases. Moreover, this decrease can be explained as a result of changing the holding cost as well. When the holding cost increases, the manufacturer keeps fewer inventories at the retailer's site.
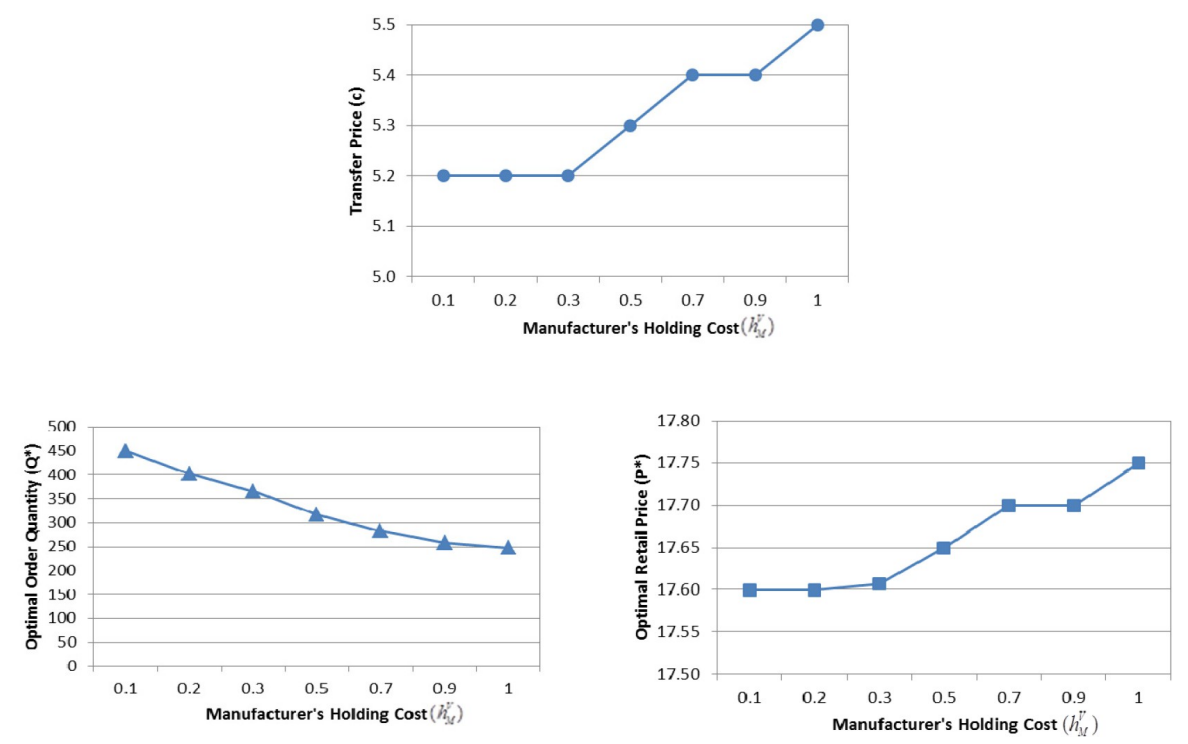

Figure 6. Impact of Manufacturer's Holding Cost on $Q^{*}, P^{*}$ and $c$ in VMI 
The impact of the production cost on optimal order quantity and optimal retail price in CPFR

Sincere there is no transfer price $(c)$ in CPFR, only $\left(P^{*}\right)$ and $\left(Q^{*}\right)$ are considered in the sensitivity analysis. Figure 7 depicts the results of the sensitivity analysis when the production cost increases in CPFR. Similar to VMI, when the production cost increases, the optimal retail price $\left(P^{*}\right)$ increases and the order quantity $\left(Q^{*}\right)$ decreases. Therefore, when the production cost $(v)$ increases, the retail price takes a higher value in order to offset the negative effect of increased production cost in the joint profit equation. When the retail price increases, then the demand decreases, and the order quantity decreases accordingly.
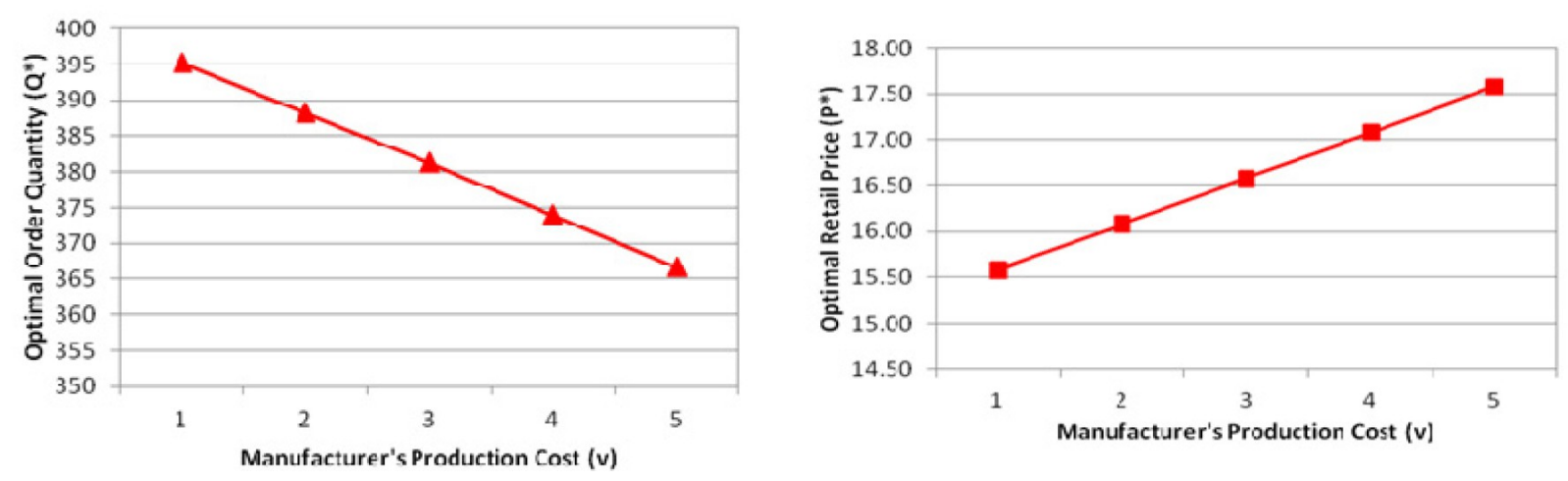

Figure 7. Impact of Production cost on $Q^{*}$ and $P^{*}$ in CPFR

Impact of the manufacturer's holding cost on optimal order quantity and optimal retail price in CPFR

Figure 8 shows that when the manufacturer's holding cost $\left(h_{M}{ }^{c}\right)$ increases, the optimal retail price $\left(P^{*}\right)$ increases and the optimal order quantity $\left(Q^{*}\right)$ decreases. As it is expected from Equation 3, when the holding cost increases, the optimal retail price must increase in order to prevent a profit loss. The fact that the manufacturer should pay more inventory holding cost makes it decrease the order quantity in order to avoid the extra cost.
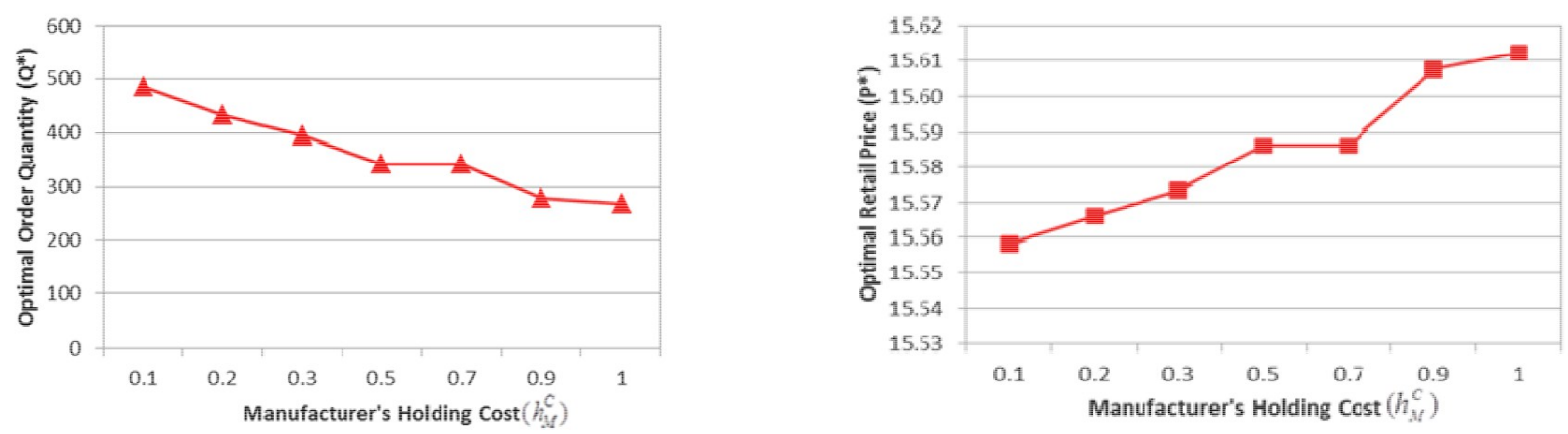

Figure 8. Impact of Manufacturer's Holding Cost on $Q^{*}$ and $P^{*}$ in CPFR 
It is shown in Figure 9 that increasing Manufacturing Holding Cost $\left(h_{M}{ }^{v}\right),\left(h_{M}{ }^{c}\right)$ and the production cost $(v)$ decrease the total profit and the total joint profit for VMI and CPFR respectively. However, CPFR still maintains a higher profit compared to VMI when the holding cost or the production cost increases. This implies that CPFR is more effective and robust than VMI in the presence of higher production cost and inventory holding cost.
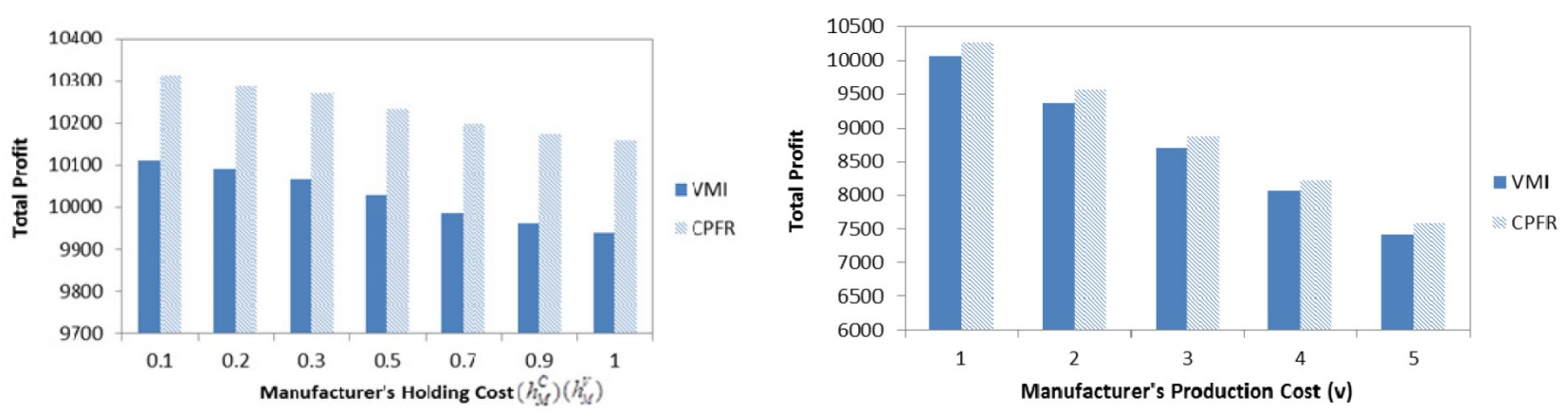

Figure 9. Impact of Manufacturing Holding Cost and Production cost on VMI and CPFR Performance

\section{Conclusion and future research}

This study examines the optimal decision making in two types of advance information sharing practices in a supply chain with one manufacturer (vendor) and one retailer: Vendor Managed Inventory (VMI) and Collaborative Planning Forecasting and Replenishment (CPFR). Two decision variables, order quantity $(Q)$ and retail price $(P)$, are optimized; the performance measure (supply chain total profit) is also examined for each of the above mechanisms under a price sensitive demand. Simulation optimization procedure is applied to find the optimal decisions.

Overall, according to the analyses, larger demand variation decreases the expected profit of the manufacturer and retailer as well as the profit of entire supply chain. Sensitivity analysis conducted in the study also reveals that increasing two parameters, production cost and manufacturer's holding cost, decrease the optimal order quantity and increase the retail price in both supply chain mechanisms. However, under all circumstances, CPFR still maintains higher overall profit, and lower retail price than those of VMI.

The conceptual framework used by this study can be a foundation for future studies of supply chain coordination and as a basis to develop new types of coordination mechanisms. Future research could consider multiple retailers, multiple manufacturers in the supply chain and examine the appropriate decision variables and other performance measures under pricesensitive demand. 


\section{References}

Attaran, M., \& Attaran, S. (2007). Collaborative supply chain management: The most promising practice for building efficient and sustainable supply chains. Business Process Management Journal, 13(3), 390-404. http://dx.doi.org/10.1108/14637150710752308

Aviv, Y. (2001). The effect of collaborative forecasting on supply chain performance. Management Science, 47(10), 1326-1343. http://dx.doi.org/10.1287/mnsc.47.10.1326.10260

Aviv, Y. (2002). Gaining benefits from joint forecasting and replenishment processes: The case of auto-correlated demand. Manufacturing \& Service Operations Management, 4(1), 55-74. http://dx.doi.org/10.1287/msom.4.1.55.285

Aviv, Y. (2004). Collaborative Forecasting and Inventory Management: Capacity Considerations. St. Louis, MO, 34.

Baganha, M.P., \& Cohen, M.A. (1998). The stabilizing effect of inventory in supply chains. Operations Research, 46(3), 72-83. http://dx.doi.org/10.1287/opre.46.3.S72

Bamford, D.R., \& Forrester, P.L. (2003). Managing planned and emergent change within an operations management environment. International Journal of Operations \& Production Management, 23(5), 546-564. http://dx.doi.org/10.1108/01443570310471857

Cachon, G.P., \& Fisher, M. (2000). Supply chain inventory management and the value of shared information. Management Science, 46(8), 1032-1048. http://dx.doi.org/10.1287/mnsc.46.8.1032.12029

Chen, F. (1998). Echelon reorder points, installation reorder points, and the value of centralized demand information. Management Science, 44(12), 221-234. http://dx.doi.org/10.1287/mnsc.44.12.S221

Chen, F., Drezner, Z., Ryan, J.K., \& Simchi-Levi, D. (2000). Quantifying the bullwhip effect in a simple supply chain: The impact of forecasting, lead times, and information. Management Science, 46(3), 436-443. http://dx.doi.org/10.1287/mnsc.46.3.436.12069

Cooke, J.A. (1998). VMI: very mixed impact? Logistics Management and Distribution.

Dana Jr, J.D., \& Petruzzi, N.C. (2001). Note: The newsvendor model with endogenous demand. Management Science, 47(11), 1488-1497. http://dx.doi.org/10.1287/mnsc.47.11.1488.10252

Disney, S.M., \& Towill, D.R. (2003). Vendor-managed inventory and bullwhip reduction in a two-level supply chain. International Journal of Operations \& Production Management, 23(6), 625-651. http://dx.doi.org/10.1108/01443570310476654 
Emerson, D., Zhou, W., \& Piramuthu, S. (2009). Goodwill, inventory penalty, and adaptive supply chain management. European Journal of Operational Research, 199(1), 130-138. http://dx.doi.org/10.1016/j.ejor.2008.11.007

Fliedner, G. (2003). CPFR: an emerging supply chain tool. Industrial Management \& Data Systems, 103(1), 14-21. http://dx.doi.org/10.1108/02635570310456850

Forrester, J.W. (1958). Industrial dynamics: a major breakthrough for decision makers. Harvard business review, 36(4), 37-66.

Ganeshan, R., Boone, T., \& Stenger, A.J. (2001). The impact of inventory and flow planning parameters on supply chain performance: An exploratory study. International Journal of Production Economics, 71(1-3), 111-118. http://dx.doi.org/10.1016/S0925-5273(00)00109-2

Gaur, V., Giloni, A., \& Seshadri, S. (2005). Information sharing in a supply chain under ARMA demand. Management Science, 51(6), 961-969. http://dx.doi.org/10.1287/mnsc.1050.0385

Gavirneni, S., Kapuscinski, R., \& Tayur, S. (1999). Value of information in capacitated supply chains. Management Science, 45(1), 16-24. http://dx.doi.org/10.1287/mnsc.45.1.16

Goodwin, J.S., \& Franklin, S.G. (1994). The beer distribution game: using simulation to teach systems thinking. Journal of Management Development, 13(8), 7-15. http://dx.doi.org/10.1108/02621719410071937

Gronalt, M., \& Rauch, P. (2008). SILVA FENNICA. Silva Fennica, 42, 1.

Holmström, J., Främling, K., Kaipia, R., \& Saranen, J. (2002). Collaborative planning forecasting and replenishment: new solutions needed for mass collaboration. Supply Chain Management: An International Journal, 7(3), 136-145. http://dx.doi.org/10.1108/13598540210436595

Holt, C.C. (1960). Planning production, inventories, and work force: Prentice Hall.

Kahn, J.A. (1987). Inventories and the Volatility of Production. The American Economic Review, 77, 667-679.

Ketzenberg, M.E., Laan, E., \& Teunter, R.H. (2006). Value of information in closed loop supply chains. Production and Operations Management, 15(3), 393-406. http://dx.doi.org/10.1111/j.1937-5956.2006.tb00253.x

Kuk, G. (2004). Effectiveness of vendor-managed inventory in the electronics industry: determinants and outcomes. Information \& management, 41(5), 645-654. http://dx.doi.org/10.1016/j.im.2003.08.002

Lau, J.S.K., Huang, G.Q., \& Mak, K. (2004). Impact of information sharing on inventory replenishment in divergent supply chains. International Journal of Production Research, 42(5), 919-941. http://dx.doi.org/10.1080/00207540310001628911 
Lee, H.L., Padmanabhan, V., \& Whang, S. (1997). Information distortion in a supply chain: the bullwhip effect. Management Science, 43(4), 546-558. http://dx.doi.org/10.1287/mnsc.43.4.546

Lee, H.L., So, K.C., \& Tang, C.S. (2000). The value of information sharing in a two-level supply chain. Management Science, 46(5), 626-643. http://dx.doi.org/10.1287/mnsc.46.5.626.12047

Magee, J.F., \& Boodman, D.M. (1967). Production planning and inventory control. Vol. 131. New York: McGraw-Hill.

Mohtadi, H., \& Kinsey, J.D. (2005). Information Exchange and Strategic Behavior in Supply Chains: Application to the Food Sector. American Journal of Agricultural Economics, 87(3), 582-599. http://dx.doi.org/10.1111/j.1467-8276.2005.00749.x

Naish, H.F. (1994). Production smoothing in the linear quadratic inventory model. The Economic, 104(425), 864-875. http://dx.doi.org/10.2307/2234980

Ouyang, Y. (2007). The effect of information sharing on supply chain stability and the bullwhip effect. European Journal of Operational Research, 182(3), 1107-1121. http://dx.doi.org/10.1016/j.ejor.2006.09.037

Raghunathan, S. (1999). Interorganizational collaborative forecasting and replenishment systems and supply chain implications. Decision Sciences, 30(4), 1053-1071. http://dx.doi.org/10.1111/j.1540-5915.1999.tb00918.x

Ramey, G., \& Ramey, V.A. (1991). Technology commitment and the cost of economic fluctuations. National Bureau of Economic Research.

Sajadieh, M.S., \& Akbari Jokar, M.R. (2009). Optimizing shipment, ordering and pricing policies in a two-stage supply chain with price-sensitive demand. Transportation Research Part E: Logistics and Transportation Review, 45(4), 564-571. http://dx.doi.org/10.1016/j.tre.2008.12.002

Sari, K. (2008). On the benefits of CPFR and VMI: A comparative simulation study. International Journal of Production Economics, 113(2), 575-586. http://dx.doi.org/10.1016/j.ijpe.2007.10.021

Simchi-Levi, D., Kaminsky, P., \& Simchi-Levi, E. (2003). Designing and managing the supply chain: concepts, strategies, and case studies. Irwin/McGraw-Hill.

Småros, J., \& Holmström, J. (2000). Viewpoint: reaching the consumer through e-grocery VMI. International Journal of Retail \& Distribution Management, 28(2), 55-61. http://dx.doi.org/10.1108/09590550010315098

Southard, P.B., \& Swenseth, S.R. (2008). Evaluating vendor-managed inventory (VMI) in non-traditional environments using simulation. International Journal of Production Economics, 116(2), 275-287. http://dx.doi.org/10.1016/j.ijpe.2008.09.007 
Sterman, J.D. (1989). Modeling managerial behavior: Misperceptions of feedback in a dynamic decision making experiment. Management Science, 321-339. http://dx.doi.org/10.1287/mnsc.35.3.321

Waller, M., Johnson, M.E., \& Davis, T. (1999). Vendor-managed inventory in the retail supply chain. Journal of Business Logistics, 20, 183-204.

Zhang, C. (2007). Design and simulation of demand information sharing in a supply chain. Simulation Modelling Practice and Theory, 15(1), 32-46. http://dx.doi.org/10.1016/j.simpat.2006.09.011

Zhao, X., Xie, J., \& Leung, J. (2002). The impact of forecasting model selection on the value of information sharing in a supply chain. European Journal of Operational Research, 142(2), 321-344. http://dx.doi.org/10.1016/S0377-2217(01)00300-9

Zhao, Y., \& Simchi-Levi, D. (2006). Performance analysis and evaluation of assemble-to-order systems with stochastic sequential lead times. Operations Research-Baltimore Then Linthicum, 54(4), 706. http://dx.doi.org/10.1287/opre.1060.0302

Journal of Industrial Engineering and Management, 2013 (www.jiem.org)

Article's contents are provided on a Attribution-Non Commercial 3.0 Creative commons license. Readers are allowed to copy, distribute and communicate article's contents, provided the author's and Journal of Industrial Engineering and Management's names are included. It must not be used for commercial purposes. To see the complete license contents, please visit http://creativecommons.org/licenses/by-nc/3.0/. 